\title{
DA LAVOURA PARA A MÁQUINA DE COSTURA: A INSERÇÃO DOS HOMENS NO POLO DE CONFECÇÕES DO AGRESTE DE PERNAMBUCO
}

Renata Milanês ${ }^{1}$

\begin{abstract}
RESUMO
Este artigo tem como foco analisar as relações de trabalho no âmbito das atividades produtivas têxteis desenvolvidas na zona rural no Polo de Confecções do Agreste de Pernambuco. Tomando como base empírica a inserção dos homens no mercado de trabalho, pretende-se realizar uma análise etnográfica com os/as agricultores(as) e/ou costureiros(as), observando também como o trabalho pluriativo da costura tem interferido na garantia da reprodução social das famílias camponesas. Este trabalho procura oferecer uma análise antropológica e etnográfica, a partir das ações e valores das pessoas que moram e trabalham nas suas próprias residências. A pesquisa de campo que orientou essas reflexões foi fruto de uma dissertação de Mestrado, na qual foram realizadas trinta entrevistas com os diversos atores que compõem o cenário deste estudo. A partir da inserção masculina no ramo da costura e da construção da representação social dessa profissão, o estudo conclui (através de uma análise geracional) que existe um conflito de identidade visível sobre o que é "ser agricultor" e "ser costureiro", elucidando possíveis resistências a esse ofício na região.
\end{abstract}

Palavras-chave: agricultura; costura; pluriatividade; polo de confecções do Agreste de Pernambuco.

\section{FROM THE CROP TO THE SEWING MACHINE: THE INSERTION OF MALE FAMILY FARMERS IN THE CLOTHING MARKET IN BRAZIL}

\begin{abstract}
This article focuses on analyzing labor relations in the context of textile production activities carried out in the homes of some rural villages in the Textile Pole of Pernambuco, also observing how the pluriactive sewing work has interfered in the guarantee of the social reproduction of the peasant families and how it has reconfigured labor relations in the region. Taking as an empirical basis the insertion of men in the labor market, we intend to carry out an ethnographic analysis with the family farmers and / or seamstresses living in the rural area of the market. This work seeks to offer an anthropological and ethnographic analysis, based on the actions and values of the people who live and work in their own homes. The field research that guided these reflections come from my Master's dissertation, in which I realized more than thirty interviews with the different actors that make up the scenario of this study. Through the male insertion in the sewing work and the construction of the social
\end{abstract}

${ }^{1}$ Graduada em Ciências Sociais (UFCG). Mestra em Ciências Sociais em Desenvolvimento, Agricultura e Sociedade (CPDA-UFRRJ). Doutoranda em Ciências Sociais em Desenvolvimento, Agricultura e Sociedade (CPDA-UFRRJ). E-mail: renatamilanes@hotmail.com 
representation of this profession, the study concludes (through a generational analysis), that there is a visible identity conflict about what it is "to be a family farmer" and "to be a seamstress" for older men, elucidating possible resistance and denials of that office.

Keywords: agriculture; clothing market in Pernambuco; pluriactivity; sewing.

\section{INTRODUÇÃO}

O Agreste de Pernambuco é conhecido nacionalmente por seu Polo de Confecções de roupas, que teve origem em meados dos anos 50, através da Feira da Sulanca e atualmente, consiste em um dos mais importantes aglomerados econômicos existentes na Região Nordeste, sendo considerado o segundo maior polo têxtil do país. Suas atividades produtivas e comerciais se encontram instaladas principalmente nas cidades de Santa Cruz do Capibaribe, Toritama e Caruaru, englobando também alguns povoados rurais do seu entorno.

Conforme foi demonstrado por Burnett (2014) a prática das feiras livres é emblemática nessa região do Agreste pernambucano, principalmente na cidade de Santa Cruz do Capibaribe, que tem sua trajetória cultural e econômica, marcada pelo comércio e pela tradição das feiras, nas quais são comercializadas mercadorias dos mais diversos tipos, como calçados de couro, produtos agrícolas ou roupas. Por ser localizada em uma região de transição, Santa Cruz do Capibaribe, conhecida como a "Capital da Sulanca", "Capital da Moda" ou "Capital das Confecções" foi historicamente marcada pelas feiras livres e seu desenvolvimento comercial também foi impulsionado pelo estabelecimento de grandes centros comerciais de cidades vizinhas.

Dentre as inúmeras configurações possíveis, o Polo tem sido caracterizado por alguns autores, como um espaço que conta com a forte presença da produção domiciliar de caráter informal (tanto na zona urbana, como na rural) e suas unidades de produção se destacam tanto por se apoiarem nas relações de trabalho familiares, como também por evidenciarem a predominância do trabalho feminino e infantil na região (VÉRAS DE OLIVEIRA, 2011; BEZERRA, 2011, SILVA, 2009).

Antes do segmento têxtil despontar como atividade principal no local, o que predominava no local, era uma economia voltada principalmente para a atividade agrícola, que por sua vez, sempre encontrou dificuldades de se sustentar, por enfrentar situações adversas, tais como a localização do município em uma das regiões mais secas do país, onde as chuvas são irregulares e escassas, como também pela falta de políticas públicas capazes de minimizar esse problema histórico (SALES, 1982, CAMPELLO, 1983).

A partir desse contexto, este artigo tem como foco analisar as relações de trabalho, no âmbito das atividades produtivas têxteis desenvolvidas nos domicílios de alguns povoados rurais no entorno do Polo, observando como o trabalho com a costura tem interferido na garantia da reprodução social das famílias camponesas e como vem reconfigurando as relações de trabalho na região. Tomando como base empírica a inserção dos homens camponeses no mercado de trabalho, pretende-se realizar uma análise etnográfica com os/as agricultores(as) e/ou costureiros(as) residentes da zona rural do Polo, com o intuito de perceber, qual o lugar que a atividade da costura ocupa hoje na reprodução social das famílias pesquisadas. Através da consolidação da atividade da costura, será analisada também a construção da representação social dessa profissão e o conflito de identidade que ela estabelece entre o "ser agricultor" e o "ser costureiro", ressaltando possíveis dilemas, sobretudo 
para os homens de mais idade, que enveredaram pelo caminho da produção de roupas.

Alguns dos questionamentos principais que este artigo pretende responder, são: $O$ aumento das atividades não-agrícolas pode ser utilizado para decretar o fim da agricultura familiar na região? Existe um conflito de identidade entre ser agricultor e ser costureiro? Como e por que os agricultores homens começaram a costurar e como eles encaram essa profissão? Qual das duas atividades eles mais gostam de exercer? Atualmente qual a principal fonte de renda das famílias rurais, a agricultura ou a confecção de roupas?

\section{METODOLOGIA}

A pesquisa de campo que orientou as reflexões deste trabalho foi fruto da minha dissertação de Mestrado, realizada em 2015 a partir de três viagens ao Agreste de Pernambuco, que totalizaram cerca de dois meses de estadia (entre 2014 - 2015), os quais eu residi na casa dos próprios trabalhadores da região. Durante este período, realizei trinta entrevistas semi-estruturadas com os diversos atores (na faixa etária de vinte a noventa anos) que compõem o cenário deste estudo, entre costureiros(as), agricultores(as), historiadores locais, representantes do poder público, comerciantes, dentre outros.

A pesquisa empírica que embasa as discussões presentes neste texto foi realizada na comunidade rural do Algodão, em dois assentamentos rurais, como também em outras pequenas propriedades no entorno da região do Agreste de Pernambuco.

Para os fins desta pesquisa utilizei também a observação participante, fazendo uso da etnografia com a intenção de compreender e reelaborar os significados e as particularidades das ações dos indivíduos nas suas práticas e representações do cotidiano. Sendo mais do que uma técnica ou método de pesquisa, a etnografia visa um processo interativo e prático que envolve situações de reelaboração entre o investigador, suas práticas e a representação dos grupos estudados (CARDOSO DE OLIVEIRA, 2004).

Este artigo, portanto, procura oferecer uma análise sob o ponto de vista antropológico, a partir das ações individuais ou coletivas, valores ou expectativas das pessoas que moram e trabalham nas suas próprias residências. Será através das experiências, narrativas, trajetórias e das categorias de pensamento dos próprios trabalhadores, que se buscará compreender as representações acerca dos processos de trabalho, da sua prática econômica e das suas vidas, levando em conta principalmente as relações familiares que se tornam estruturantes nesse processo.

\section{DA ‘FEIRA DA SULANCA’ AO SEGUNDO MAIOR POLO TÊXTIL DO BRASIL}

Santa Cruz do Capibaribe é a terceira maior cidade do Agreste de Pernambuco, ficando atrás apenas de Caruaru e Garanhuns, tendo uma população estimada de aproximadamente 107.937 habitantes, segundo o IBGE/2019². Santa Cruz fica a $190 \mathrm{~km}$ de Recife e possui o clima semiárido na maior parte do ano. O município pertence à Microrregião do Alto Capibaribe, se localiza a oeste de um relevo montanhoso e sofre consequências dessa posição, que são traduzidas geralmente na escassez de chuvas.

\footnotetext{
${ }^{2}$ Fonte: https://cidades.ibge.gov.br/brasil/pe/santa-cruz-do-capibaribe/panorama (Acesso em 3 de Fevereiro de 2020)
} 
Campello (1983) afirma que até meados da década de 60, a cidade era considerada um centro urbano inexpressivo dentro do contexto de seu Estado, pois apenas correspondia a um dos muitos municípios de Pernambuco, "com atividades urbanas restritas às funções administrativas e a um pequeno comércio local, tendo na feira o ponto de convergência dos produtos e da população" (CAMPELLO, 1983, p. 36), fato semelhante ao que pode ser encontrado nas pequenas cidades do interior do Nordeste. Entretanto, por ser localizada em uma região de transição, Santa Cruz foi historicamente marcada pelas feiras e seu desenvolvimento comercial também foi impulsionado pelo estabelecimento de grandes centros comerciais de cidades vizinhas, como Campina Grande (PB) e Caruaru (PE).

O momento inicial da atividade de confecções na cidade de Santa Cruz do Capibaribe, se caracteriza pela sua integração econômica com as feiras locais e com a capital do Estado, no qual em meados de 1950 alguns comerciantes se deslocavam para Recife, levando galinhas, carvão, queijo, entre outros produtos locais para vender, e retornavam com retalhos de tecidos para suas casas (LIRA, 2006). Nesse período, os retalhos de tecido eram obtidos em Recife, inicialmente nas fábricas têxteis de Camaragibe, Torre, Macaxeira, Othon e Paulista, e eram comercializados na feira livre de Santa Cruz do Capibaribe (CAMPELLO, 1983). Tais pedaços de tecido eram os restos e refugos de grandes fábricas têxteis, que eram descartados no lixo e recolhidos por esses comerciantes que os vendiam a baixo custo aos moradores da região.

De início, as mulheres adquiriam esses retalhos, os convertiam em vestimentas de uso familiar e, posteriormente, em colchas de retalho (denominadas de "cobertas" pelos moradores locais), que passaram a ser comercializadas ou até mesmo trocadas por galinhas e outras mercadorias na feira. Nessa época, algumas mulheres tinham uma máquina em casa e geralmente costuravam para os membros de sua família vestimentas de uso pessoal. Com o passar do tempo, além das colchas, começou-se a produzir também algumas roupas, como shorts infantis, denominados de "milonga", saias, blusas e outras peças que tinham maior facilidade de serem moldadas e feitas com "emendados" de tecido. Todas as mercadorias tinham como principal atrativo o preço baixo, as peças eram simples, sem muita diversificação e se destinavam geralmente às populações de baixa renda.

Convém destacar que, na gênese do surgimento da produção e comercialização de roupas, o ofício da costura era exclusivamente feminino. No discurso local, algumas pessoas reconhecem esse pioneirismo e destacam historicamente a importância precursora das mulheres como agentes responsáveis pelo desenvolvimento da atividade de confecções na região. Os homens por sua vez, ficavam responsáveis pela comercialização dos produtos. No entanto, com o passar do tempo, os homens também passam a se inserir nesse ramo de atividade, pois para muitos o "mundo da sulanca" se estabelecia como uma grande oportunidade de trabalho, e esta era uma das poucas fontes de renda, presentes na região. Portanto, embora as mulheres tenham sido incorporadas mais fortemente pela atividade da costura, atualmente os homens também realizam esse trabalho.

É importante pontuar que a arte da costura na região vem se reproduzindo ao longo de décadas e de gerações, através da transmissão oral e da experiência prática daqueles que já estão estabilizados nessa função. Dessa maneira, as pessoas que costuram, iniciaram nessa profissão e continuam se mantendo até hoje, não através de cursos de corte e costura ou de um aprendizado formal, mas sim através de um circuito de transmissão de técnicas baseadas na sabedoria comum coletiva, que é compartilhada e ensinada por membros da família ou por relações de vizinhança e amizade ainda na infância. 
Figura 1 - Costureiras vendendo seus produtos em Santa Cruz do Capibaribe

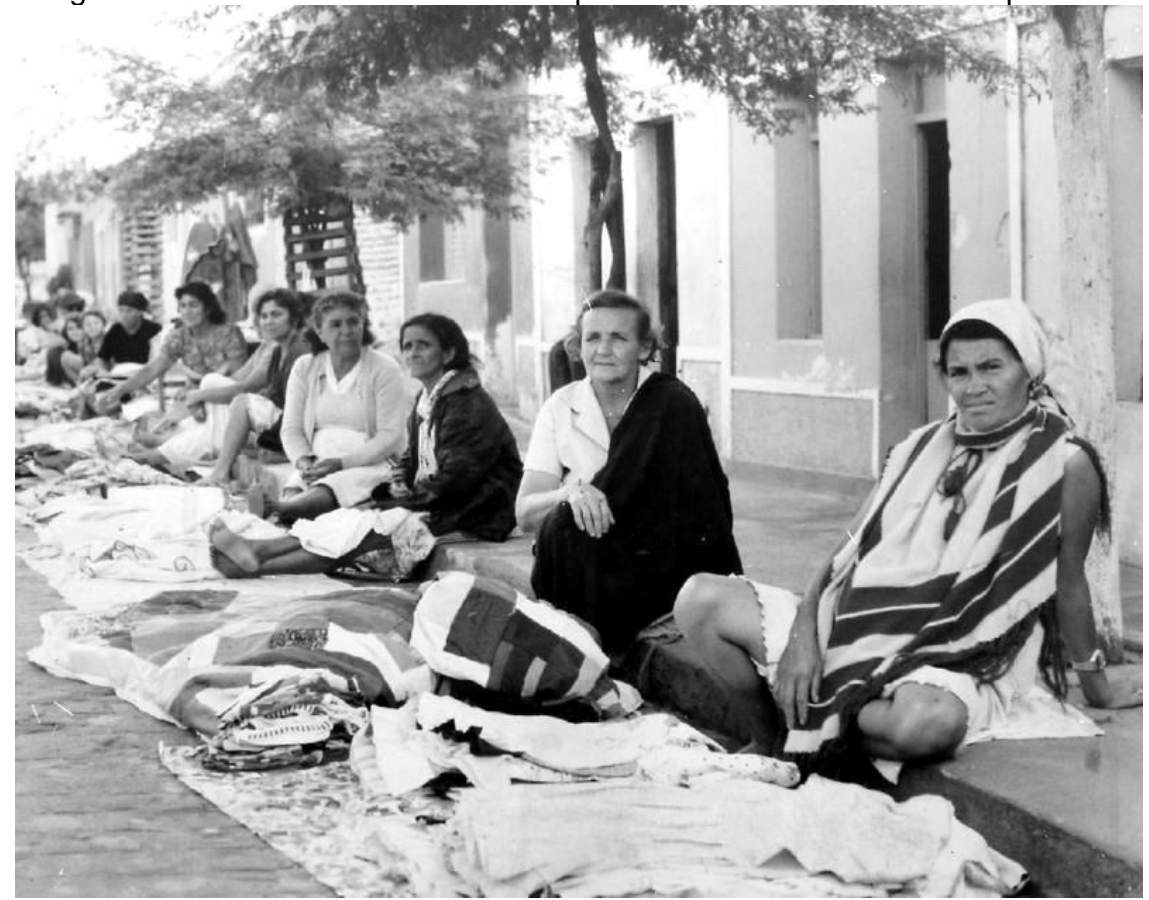

Fonte: Autor e época não identificados. Arquivo pessoal cedido por José Góis.

Na década de 60 e 70, o sucesso das vendas fez com que a oferta de roupas se expandisse, pressionando a busca por uma maior quantidade de tecidos para abastecer a produção da sulanca. Estes começaram a ser trazidos do Rio de Janeiro e de São Paulo, pelos caminhoneiros da época, e consistiam em retalhos e resíduos que sobravam das confecções das grandes cidades do Sudeste. Isso explica a nomenclatura da 'Sulanca' que significa a junção dos termos "sul" (local de onde os tecidos vinham) e "helanca" (tipo de tecido utilizado para a fabricação das peças) (CAMPELLO, 1983).

Ao retornarem de São Paulo, os caminhoneiros vendiam os retalhos e as transações ficavam anotadas no caderno do comprador e do vendedor, as relações se baseavam no "fiado" e na confiança. As costureiras adquiriam os retalhos e só quando vendiam as mercadorias feitas por elas, é que o pagamento do tecido era realizado, e a partir do acúmulo do dinheiro que recebiam, os caminhoneiros voltavam a viajar para São Paulo.

Ao passo que os tecidos eram trazidos do Sudeste do país, o sucesso na comercialização dos produtos têxteis fez com que tais atividades fossem se expandindo, atraindo cada vez mais pessoas, compradores e empreendimentos em Pernambuco. Além disso, a partir dos anos 70, começa a se destacar fortemente na região a figura dos sulanqueiros (comerciantes homens), que viajavam pelo Norte e Nordeste vendendo as mercadorias. Tal fator foi crucial para propagar a imagem de Santa Cruz do Capibaribe, escoar a produção, bem como para fortalecer e criar redes de rotas comerciais (BURNETT, 2013).

Os sulanqueiros pegavam algumas peças de roupas, geralmente feitas pelas suas esposas, ou compradas de outras mulheres e com as mercadorias em mãos, 
passavam semanas viajando por cidades e Estados do Norte e Nordeste, expondo os produtos no chão, dormindo no próprio meio de transporte e vivendo longe de casa. Cada viagem durava cerca de quinze dias, enquanto isso, as mulheres da região ficavam nas suas casas costurando mais roupas, porque quando eles voltavam, ficavam poucos dias no seu local de moradia e recomeçavam todo o processo novamente.

A entrada desses comerciantes no mundo da sulanca nos permite perceber que nessa época inicial de estruturação do mercado, embora o produto têxtil fosse confeccionado por mulheres, em alguns casos, ele só começa a entrar no circuito comercial inter-regional por meio da figura masculina, a exemplo dos sulanqueiros. Destarte, é por intermédio dos homens, que os retalhos de tecido passam a se tornar mercadorias para além das fronteiras da cidade de Santa Cruz do Capibaribe, pois, enquanto as mulheres costuravam em casa, seus maridos se mantinham a frente das negociações e comercializavam os produtos em outras cidades e Estados.

Figura 2 - Sulanqueiros vendendo a mercadoria em uma de suas viagens

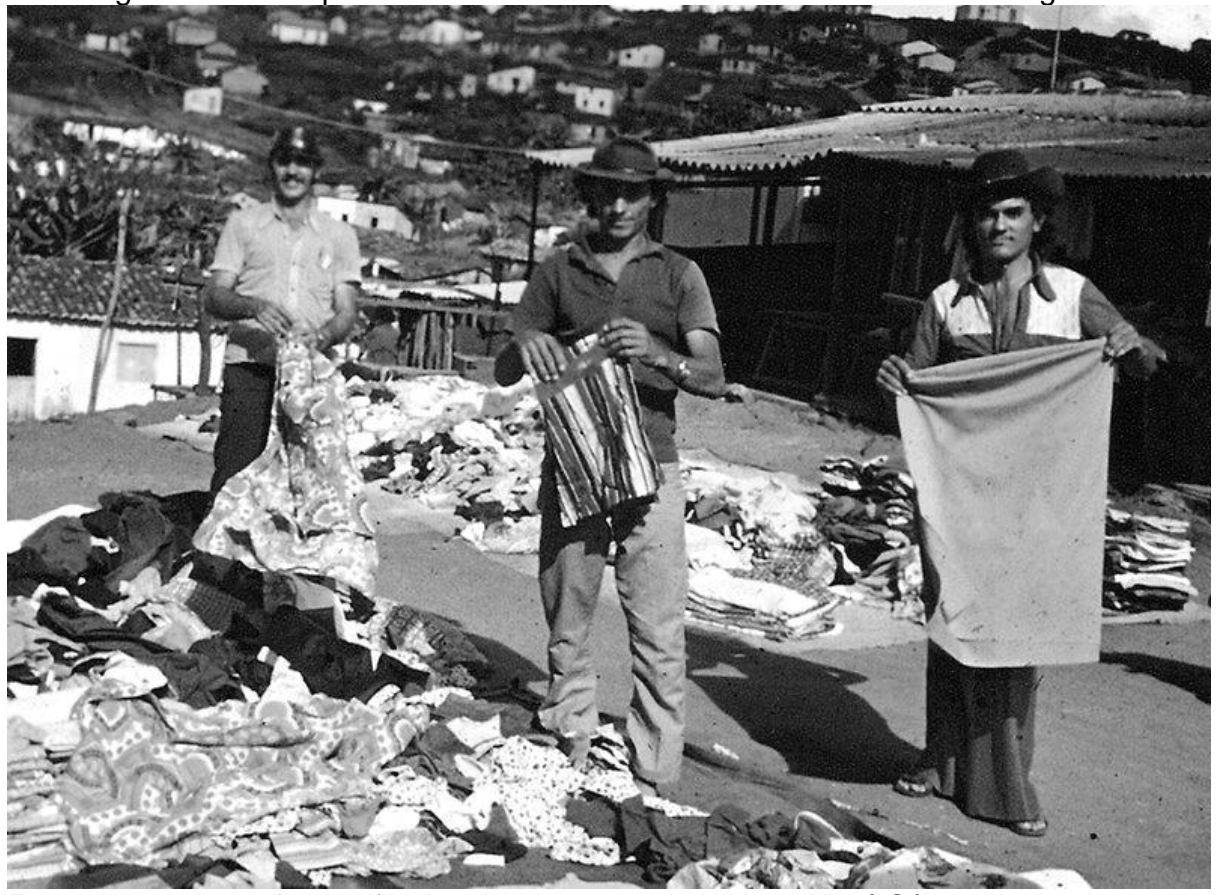

Fonte: Autor e data não identificados. Arquivo pessoal cedido por José Góis

Para Burnett (2013), esse papel exercido por inúmeros homens era importante, porque propagava e divulgava a imagem da sulanca para outras regiões, ampliando sua área de atuação para além de Pernambuco e criando um circuito comercial de maior abrangência.

O "negócio deu certo" e o sucesso nas vendas com a ampliação das confecções se fez de modo bastante intenso, principalmente nas décadas de 60 e 70. A partir desse momento, começa a ser bastante comum nas residências locais, a existência de uma ou duas máquinas de costura, nas quais as mulheres confeccionavam roupas por conta própria ou por encomenda. 
Nessa época, muitas pessoas saíram do meio rural, venderam animais ou sua pequena produção agrícola e empregaram o dinheiro na aquisição de uma máquina de costura. Já os que se mantiveram no campo, acabaram se engajando na atividade de confecções, adquirindo muitas vezes máquinas de segunda mão e montando suas próprias confecções domiciliares nos sítios em que viviam.

As décadas de 80 e 90 constituíram o auge do desenvolvimento produtivo e comercial da região. Nessa época ocorreu o retorno de várias pessoas que antes haviam migrado para o Sul/Sudeste do país, com o intuito de voltar para investirem no ramo de confecções. Aliado a esse retorno, surgiu também um fluxo de migração rural dos sítios do Agreste de Pernambuco e até mesmo de Estados vizinhos, para o Polo, todos em busca de emprego, o que acarretou um demasiado aumento populacional nas três cidades principais: Caruaru, Toritama e Santa Cruz. Além do aumento populacional, o crescimento econômico da região ganhou destaque e foi cada vez mais impulsionado pela fabricação de roupas, ao passo que se tornou necessário aumentar e ampliar demasiadamente a produção, pois semanalmente a região passou a receber muitos compradores de todos os lugares do país (CAMPELLO, 1983; LYRA, 2005).

A "Feira da Sulanca" passa a se chamar "Polo de Confecções do Agreste de Pernambuco", a partir de 2000. Isso decorre do empenho por parte de alguns empresários e comerciantes em desconstruir a imagem da sulanca, que na atualidade é relacionada a produtos de pouca qualidade, e seu uso pode ser pejorativo. Dessa maneira, como Véras de Oliveira (2011) observa: "Operou-se uma reelaboração discursiva visando pôr no lugar da 'Feira da Sulanca' o 'Polo de Confecções'; no lugar de 'sulanqueiro', a denominação 'empresário' ou 'empreendedor'” (p. 23).

\section{A COMBINAÇÃO DE ATIVIDADES AGRÍCOLAS E NÃO-AGRíCOLAS NO AGRESTE PERNAMBUCANO}

No Brasil, várias têm sido as abordagens que focalizam na importância da das atividades não-agrícolas exercidas pelas famílias rurais como formas de rendas complementares que viabilizariam a reprodução dessas unidades (GARCIA JR. 1989, CARNEIRO, 1998, SCHNEIDER, 2003, GRAZIANO DA SILVA E DEL GROSSI, 2000). Virgolin, Hillig e Froehlich (2015), por exemplo, apontam que a realização de atividades não-agrícolas no meio rural vem sendo historicamente abordada através de discussões que utilizam termos como: "'agricultor em tempo parcial', 'atividades não-agrícolas no meio rural', 'empregos múltiplos', 'fontes de renda diversificadas' e 'pluriatividade'” (p. 117).

O que se percebe através desses estudos e suas diferentes contribuições é que, em certa medida, o desenvolvimento dos espaços rurais nem sempre depende exclusivamente apenas do dinamismo do setor agrícola, mas sim da sua capacidade de atrair outras atividades econômicas e outros interesses capazes de realizar uma profunda "ressignificação" de suas próprias dinâmicas sociais. Nesse sentido, para além do seu caráter produtivo, é importante também perceber o rural como um espaço de múltiplas dimensões que transcendem suas funções agrícolas ou agropecuárias.

Tepicht (1973) sugere que, em meio a um cenário no qual a atividade agrícola não tem, ou perde, a capacidade de suprir a manutenção da família, as estratégias das famílias camponesas podem se voltar para a busca de outras formas de renda, se submetendo e se adaptando a uma economia que muitas vezes "se aproveita de sua fraca mobilidade profissional" (TEPICHT, 1983, p. 26). Além disso, em algumas situações, como é o caso do objeto empírico desta pesquisa, ao dispor de poucos recursos e de muitas restrições para potencializar a força produtiva da sua unidade 
doméstica, o trabalho não-agrícola ou pluriativo pode se tornar para o camponês uma "necessidade estrutural", nos termos de Wanderley (1998).

De início, imaginava que a confecção de roupas fosse a primeira das atividades que, articuladas com a agricultura, complementava a renda das famílias rurais da região, mas ao desenvolver a pesquisa percebi que no povoado do Algodão e até mesmo no Agreste pernambucano em geral, as próprias famílias como um todo, "sempre tiveram que se virar". A exemplo disso, temos o agricultor Chico Carola, de 58 anos, morador do Sítio Algodão, que observa com muita relevância o fato de que quando "o inverno é ruim", as mulheres ficam trabalhando na sulanca e os homens "ficam se virando", com serviços de construção civil, fazendo empréstimos no banco, e também costurando, visando garantir a reprodução do núcleo familiar.

A pesquisa de campo pode revelar que a aposentadoria, a costura, o trabalho com a construção civil e o Bolsa Família são indicadas como as principais fontes de renda local, na atualidade. Se hoje a maior parte da mão de obra ociosa agrícola encontra abrigo na confecção de roupas, antes, muitas foram as estratégias perseguidas por essas famílias dentro do exercício cotidiano de sua condição camponesa permanentemente ameaçada, que sempre exigiu a venda da força de trabalho para além das suas propriedades ou a busca de outros meios de manutenção da reprodução familiar.

No passado, grande parte dos moradores locais não possuía instrumentos de produção, nem condições de desenvolverem adequadamente as atividades agrícolas nas suas pequenas propriedades. O único elemento que eles dispunham na verdade, era a força de trabalho, que não tardou em ser vendida para que se angariasse recursos que permitissem a manutenção da família. É por esse motivo, que o "trabalho alugado" enquanto uma estratégia dos agricultores mais pobres, se repetiu na região por várias gerações e fez parte da história de vida de todos os pequenos proprietários que entrevistei. Essa estratégia do trabalho alugado se manteve por muito tempo como uma das formas mais comuns e mais recorrentes de se complementar a subsistência familiar, obtendo dinheiro, ou alimentos através da venda da mão de obra, principalmente dos homens. Para Garcia Jr. (1983), trabalhar alugado significa, reconhecer a insuficiência do trabalho familiar materializado no roçado.

Além do trabalho alugado, pude identificar também outras atividades e estratégias que foram capazes de garantir historicamente o sustento das famílias locais, como por exemplo, a comercialização dos produtos agrícolas em feiras, o trabalho nas frentes de emergência nas secas, as migrações, o trabalho na construção civil (no caso dos homens), o trabalho de empregada doméstica (no caso das mulheres) e também a inserção na confecção e comercialização de roupas.

Semelhante ao caso do Brejo paraibano analisado por Garcia Jr. (1989), no Agreste pernambucano, a prática da combinação das atividades agrícolas com nãoagrícolas, não corresponde a um fenômeno particular, que é estranho a lógica de reprodução social camponesa local, mas ao contrário, foi, e é, desde sempre um dos múltiplos mecanismos que são acionados para complementar a renda das famílias camponesas estudadas. Dessa maneira, o possível recurso às múltiplas e diversificadas atividades não estaria nesse contexto, "rompendo com um padrão de reprodução social, mas ao contrário, seria a expressão de uma maneira de exercer a condição de agricultor", conforme aponta Carneiro, 2006 (p. 175).

O que fica evidente através do caso do Agreste pernambucano, é que as dificuldades crescentes que sempre afetaram a agricultura acabaram se impondo historicamente como obstáculos para a manutenção das famílias. Nesse sentido, o crescimento do setor de confecções acabou estimulando outros arranjos na lógica de reprodução social. Acredita-se que muitas vezes, o trabalho não-agrícola pode ser 
considerado como uma "resposta" ou até mesmo uma forma de resistência em meio às crises econômicas, sociais e até mesmo climáticas em que estão envolvidas as famílias. Carneiro (1996), por exemplo, observou no caso de agricultores em regiões de montanha na França, que os espaços abertos para a prática de atividades complementares não-agrícolas são em sua maior parte, as regiões desfavoráveis ou que se encontram incapacitadas para a intensificação da agricultura.

Destarte, o que aparenta estar em curso na região do Agreste pernambucano é um processo de revitalização das formas de produção e de reprodução da força de trabalho, que combinaria a atividade da costura com a atividade agrícola, se configurando assim o que se tem designado como fenômeno da pluriatividade, tal como sugere Mattei ( 2007).

Para Schneider (2003), a noção de pluriatividade, embora seja bastante genérica, pode ser definida resumidamente como a combinação de duas ou mais atividades realizadas pelos camponeses, sendo uma delas a agricultura. $\mathrm{O}$ autor acredita que a pluriatividade não é um acontecimento marginal ou transitório confinado a determinadas situações, como se pode supor, mas também não representa um processo com tendência à generalização para todas as áreas rurais existentes.

Em acordo com Wanderley (1998), acredita-se que a pluriatividade não representa a desagregação da agricultura camponesa, mas pode contribuir para a viabilização de estratégias de reprodução presentes e futuras com as quais a família pode contar. Além disso, ela pode representar um processo de diversificação ocupacional e produtiva da população rural, provavelmente relacionada com 0 crescimento da mercantilização econômica e social.

A pluriatividade pode representar também a possibilidade de novas formas da produção que de fato começam a se desenvolver recentemente, como também pode expressar antigas práticas camponesas que sempre existiram, mas que podem passar a assumir novos significados, como é o caso do campo empírico desta pesquisa, no qual a combinação das atividades agrícolas com outras não-agrícolas para a manutenção familiar das populações do campo, não é um fato novo no local. Além disso, semelhante ao que observam Virgolin, Hillig e Froehlich (2015), no Sul do Brasil, observa-se que essas famílias rurais do Agreste pernambucano buscam através da pluriatividade novas possibilidades de utilização da força de trabalho disponível, procurando evitar que os membros das famílias migrem para outros locais.

Outro elemento bastante pertinente nas entrevistas realizadas, diz respeito à alusão ao passado fortemente agrícola como um "tempo sofrido", uma "época difícil", de "trabalho pesado", pobreza e penosidade. Tais referências contrastam com as percepções do presente, já firmado nas atividades das confecções, que são associadas sempre a um "tempo mais fácil", de "menos sofrimento", de menos cansaço, de renda garantida. Ao estudar o trabalho rural nas cinco regiões do Brasil, em épocas diferentes, Paulilo (1987) observa que as definições de trabalho "leve" e "pesado" são categorias que variam não apenas devido a qualidade do esforço despendido nas atividades, mas sim conforme o sexo de quem o executa.

O que se percebe no caso do Agreste pernambucano, por exemplo, é que o passado de "não ter nada", começa a ser transformado e relatado através da sulanca, que é vista como algo que melhorou a vida da população local, porque emprega muitas pessoas na atualidade. A ideia de que a sulanca representou uma melhora na vida dessas pessoas, faz parte de uma memória construída coletivamente, que também pode ser percebida na fala de José:

A sulanca melhorou a vida dessa região aqui toda que abrange Santa Cruz e o Polo, porque mesmo para o agricultor, mesmo que ele não saiba tirar um fiapo de linha da sulanca, mas tem 
alguém lá tirando o fiapo e pagando ao agricultor aqui para ele fazer uma coisa, pra ele fazer outra. O dinheiro que mais gira aqui é o da sulanca.

Através desse relato, é interessante notar que José percebe a complexidade da própria economia que a sulanca movimenta na região, pois reconhece que além de melhorar a vida das pessoas, até mesmo aquelas que não participam diretamente das atividades de confecção ou do comércio, dependem diretamente do dinheiro movimentado através do Polo, fato este que o faz afirmar que a maior parte do dinheiro que gira na região é o das confecções de roupas e não o da agricultura.

Outro agricultor entrevistado também afirma que as pessoas da zona rural, geralmente reinvestem a renda obtida com a produção de roupas na roça, pois em suas palavras: "hoje em dia a renda daqui da agricultura é pouca, mas eu crio umas cabras, aí mato um bode e vendo a carne, vendo um porco, vendo o ovo da galinha, aí mistura tudo com o ganho da sulanca".

Essas configurações destacadas nas falas acima, demonstram um processo de via dupla, pois do mesmo modo que a renda da agricultura pode ser investida na sulanca, o contrário também acontece. As experiências dos agricultores e costureiros locais deixam evidente que o próprio dinheiro da sulanca não só é reinvestido na agricultura e na criação dos animais, como também permite que eles possam contratar alguém para auxiliar na lavoura. Diante da dificuldade de se sustentar, as atividades agrícolas, assim como seus rendimentos acabam assumindo um peso menor nos domicílios rurais, mas isso não impede que os ganhos obtidos com a agricultura também possam ser direcionados para as confecções.

\section{AGRICULTORES OU COSTUREIROS? A INSERÇÃO MASCULINA NA PRODUÇÃO DE ROUPAS}

Uma impressão inicial que tive e que na verdade acabou se configurando como uma hipótese de pesquisa era a de que quanto mais perto a comunidade rural, fosse do Polo, haveria a tendência de uma menor produção agrícola da mesma, pois ela estaria vinculada mais facilmente e diretamente com a sulanca. A pesquisa de campo conseguiu revelar que, de fato, as comunidades rurais mais próximas dos centros urbanos de Santa Cruz, Toritama e Caruaru acabaram sendo absorvidas mais intensamente no que diz respeito às atividades de confecções, do que os sítios que ficam mais distantes geograficamente destes municípios.

Isso acontece, porque fica mais "fácil" e mais "barato" para os contratantes levar o tecido que vai ser costurado e isso facilita à logística. Esse interesse da contratação da mão de obra do campo se justifica ainda pelo preço mais baixo da mão de obra rural em comparação aos trabalhadores da cidade, para desenvolverem a mesma atividade. Como bem observa o Secretário de Agricultura do município de Taquaritinga do Norte, quando passamos pela cidade de Santa Cruz do Capibaribe é comum encontrarmos placas com os dizeres "PRECISA-SE DE COSTUREIRA". Para ele, é diante dessa situação que, "a zona rural passa a cobrir essa carência da mão de obra" que está cada vez mais difícil de ser encontrada na cidade, porque quase todas as pessoas já estão ocupadas em suas confecções domiciliares. Além disso, como afirma, nos casos dos empresários informais que não são registrados, e terceirizam a produção, eles acabam se livrando dos encargos sociais e das fiscalizações trabalhistas.

É importante considerar que a inserção dos camponeses no trabalho nãoagrícola da costura na região, se iniciou através das mulheres com a ampla expansão das confecções de roupas, que supostamente abriu espaço considerável para que 
elas conseguissem se inserir no exercício dessas atividades industriais. Dessa maneira, foram as mulheres que começaram trabalhando como costureiras para contribuírem com a manutenção da reprodução do grupo familiar, os homens só começam a entrar nesta função mais tardiamente, motivados pela oportunidade que este mercado de trabalho vinha oferecendo e também pelo ganho que a costura poderia proporcioná-los, ao contrário da agricultura, que como já foi dito sempre teve dificuldade de se sustentar e de representar rendimentos estáveis.

Tendo em vista esse fator, é relevante frisar que embora a costura incorpore vários homens na atualidade, essa atividade é legitimada culturalmente e construída histórica e socialmente como uma tarefa tipicamente feminina, e constitui em algumas sociedades um saber considerado "natural", expressando por vezes a expectativa de um modelo tradicional que a mulher enquanto esposa ou mãe deve exercer. Como bem observa Cabral (2007), a mulher, antes mesmo de receber a educação formal, aprende algumas tarefas, que pela cultura local, Ihes são impostas a título de trabalho exclusivamente feminino, como é o caso da costura, por exemplo.

No começo da sulanca, algumas mulheres tinham uma máquina em casa e geralmente costuravam para os membros de sua família vestimentas de uso pessoal. Com a expansão da confecção e comercialização de roupas no local, as atividades da costura, anteriormente exercidas no âmbito do lar e de forma gratuita, passam a ser apropriadas pela confecção e pelo comércio das feiras locais, abrindo espaço para a entrada da mão de obra feminina no mercado de trabalho (BEZERRA, 2011).

Dessa maneira, a habilidade de costurar, junto à necessidade de reinventar estratégias de sobrevivência e a expansão das atividades produtivas, fez com que as mulheres do Agreste de Pernambuco se engajassem cada vez mais no ramo da confecção. A costura, portanto, se tornou para elas uma importante oportunidade de trabalho, possibilitando a obtenção de uma remuneração própria através dessa atividade. Nesse sentido, a costura primeiro apareceu como uma atividade doméstica das esposas e mães, para só depois ser incorporada como uma fonte de renda (também) para os homens e como algo que pode ser vendido "pra fora" dos sítios, passando a ser vista como uma profissão e não apenas como "um dom" ou um ofício exclusivamente feminino.

O interesse de observar como se dava essa expansão da atividade da costura para as zonas rurais já estava presente nas minhas reflexões muito antes da conversa que tive com o Secretário de Agricultura do município e de fato só pude compreender melhor, depois que escutei as histórias de inserção dos agricultores, sobretudo dos homens, no mundo da sulanca.

Para o agricultor Chico Carola, por exemplo, a entrada dos homens na rota das confecções se deu "por falta de trabalho na roça", pois "não tinha mais do que eles viverem, daí foram aparecendo uns serviços na cidade com esse negócio de costura, aí uns foram aprendendo e passando para os outros". Entretanto, cabe salientar que as primeiras atividades exercidas por alguns deles não foi a costura, porque muitos começaram nas fábricas e nos fabricos tirando ponta de linha, embolsando, cortando, e só depois passaram a costurar, pois esta última atividade é a que apresentava uma melhor remuneração, dentre todas as citadas anteriormente.

É relevante destacar ainda, que na região, embora em algumas funções haja um sistema de estratificação ocupacional, a atuação em atividades que são culturalmente e socialmente tidas como femininas, relacionadas ao ramo de confecções (como costurar, bordar, passar, etc), passaram a sofrer alterações e modificações, pois com facilidade encontramos homens, jovens e adultos, exercendo profissionalmente tais ofícios, as quais antes só eram desempenhadas por mulheres no trabalho e na vida doméstica. 
Diferente de outros polos de confecções têxteis brasileiros, uma especificidade da região estudada é que, no Polo de Pernambuco, a incorporação de homens em atividades tidas como "femininas" foi sendo, com o tempo, e através de gerações, naturalizada. Nenhum dos homens entrevistados afirma que sofreu algum tipo de represália ou mau julgamento por serem costureiros. Isso implica dizer que hoje, a aceitação do fenômeno é tida localmente como algo natural, que não envolve piadas, ou estigmatização social. O próprio processo de reestruturação das atividades do Polo trouxe uma nova forma de ver a temática do "homem realizar trabalho de mulher".

Como afirma Espírito Santo (2013), em sua pesquisa sobre a sulanca, o possível preconceito inicial que em décadas passadas pode ter existido, com o tempo foi sendo deslocado pela "oportunidade formidável de trabalho que a costura na sulanca representava e, por conseguinte, os homens constituem hoje boa parte do contingente dos trabalhadores" (p. 194). Esse fator é interessante de ser observado por ocorrer justamente no Nordeste brasileiro, por vezes, erroneamente referenciado, estigmatizado e estereotipado como uma região machista e conservadora. Já em outras regiões do país, essa naturalização dos papéis de gênero no setor têxtil não ocorre da mesma maneira. Lima (2009), por exemplo, em seu estudo nas confecções de roupas em Cianorte, no Paraná, observa que diferente do que ocorre em Pernambuco, os homens que trabalhavam em lavanderias têxteis da cidade, demonstravam muito constrangimento e até se escondiam da pesquisadora para não serem vistos realizando atividades vistas como femininas.

Entretanto, no Polo pernambucano, se aparentemente a maioria dos homens agricultores, assume que costura por necessidade e que não tem problema nenhum com isso, percebe-se que essa inserção na atividade da costura em alguns casos vem acompanhada por um processo de resistência, sobretudo entre os homens mais velhos, pois muitos relatam que não gostam de realizar tal atividade e apenas fazem isso devido aos rendimentos financeiros obtidos com a costura de roupas e porque não têm condições de se dedicarem exclusivamente à agricultura.

Esses elementos revelam aspectos distintos se forem analisados através das dimensões de gênero e gerações, pois ao comparar os discursos dos homens e mulheres, dos jovens, adultos e idosos, percebe-se que as atividades agrícolas na região que conseguem se manter atualmente, são realizadas mais por homens de idade média ou avançada. Já os jovens e as mulheres acabaram se incorporando mais fortemente nas atividades da costura e demonstram vislumbrar um retorno ou um início de trajetória pautada na agricultura ou na pecuária.

O que acontece no Polo, reafirma o que Virgolin, Hillig e Froehlich (2015) já haviam constatado no Sul do país, pois as entrevistas obtidas na pesquisa de campo nos fazem associar o sentido do trabalho para os agricultores a uma questão geracional e familiar, ou seja, "este está fortemente associado às experiências de trabalho vivenciadas pelos próprios entrevistados no passado e pelas antigas gerações da família" (VIRGOLIN, HILLIG e FROEHLICH, p. 124, 2015). Isso implica dizer que o sentido do trabalho agrícola e o trabalho da costura varia de acordo com a percepção dos diferentes indivíduos pesquisados.

A baixa rentabilidade oferecida pelo roçado ou pela pecuária, por exemplo, são vistos pelos jovens e pelas mulheres como desestimulantes e o trabalho com a costura no Polo surge como uma "oportunidade" de inserção numa economia mais monetarizada e rentável, possibilitando uma "melhora de vida" e também uma maior autonomia e independência financeira destes. Através de uma análise das entrevistas, nota-se que desde o surgimento da sulanca, em vários casos, o homem deixa de ser o único, ou o principal responsável e provedor da família. Pois, com a entrada das 
mulheres no mercado de trabalho, elas passam cada vez mais a ter dinheiro e a arcar com os gastos da casa, algumas vezes, até mais do que os próprios homens.

Uma das costureiras entrevistadas ao comparar a sua infância e o trabalho na roça com os dias atuais, afirma: "hoje em dia a gente vive mais independente, ganha mais dinheiro, nem se compara com antigamente. Eu trabalho porque eu preciso e porque eu gosto de costurar, foi esse serviço que me deu dinheiro até hoje". Ela assume que as atividades agrícolas nunca foram capazes de lhe dar algum tipo de rendimento, por isso, defende que gosta de costurar e que foi através dessa atividade que ela conseguiu obter algum tipo de retorno monetário e construir sua vida.

Essa configuração pode ser explicada através das análises de Paulilo (2004), pois como bem demonstra a autora, embora no Brasil exista a agricultura familiar como um tipo de empreendimento, a categoria profissional 'trabalhador familiar' é inexistente. Isso implica dizer que nas estatísticas oficiais, com exceção do homem (considerado como o principal responsável), a esposa e os filhos figuram apenas como "membros não remunerados da família". O que segundo Paulilo (2004) representa um reconhecimento implícito de que ele é quem tem maior poder sobre a renda familiar.

No caso do Agreste pernambucano, o surgimento da sulanca em Santa Cruz do Capibaribe representa um fator importante para as mulheres da região, pois marca a primeira vez que muitas delas conseguem ter acesso a algum tipo de renda. Dessa maneira, o trabalho com a costura tem proporcionado para as mulheres não só um ganho monetário, mas também tem lhes dado poder de compra e de administração das finanças, pois a partir do momento que começam a ser remuneradas, muitas não precisam mais pedir ou dar satisfações aos maridos sobre o que, e aonde vão empregar o dinheiro que ganham.

Aliado a este fato, existe ainda a questão de que a penosidade das atividades exercidas pelo agricultor, sempre relacionadas ao "sol quente", ao trabalho árduo e à força física acabam sendo comparadas, se opondo ao trabalho da confecção, que é realizado na sombra, dentro de casa e que mesmo apesar do barulho das máquinas, do estresse e dos ritmos de trabalho, acaba representando uma renda garantida que não irá depender de agravantes climáticos ou de uma divisão pautada na hierarquia familiar. É importante observar também que o fato da costura poder ser realizada nos domicílios acaba fazendo com que alguns jovens prefiram continuar nas suas respectivas comunidades rurais, sem a necessidade de migrar para as zonas urbanas em busca de trabalho, o que pode até reduzir em certa medida o esvaziamento rural da região.

Embora os jovens e as mulheres pesquisados quase não realizem mais atividades agrícolas, pois têm se dedicado mais ao trabalho com a confecção de roupas, nos sítios e assentamentos, o trabalho na roça, mesmo encontrando dificuldades, continua se fazendo presente através dos homens mais velhos, que resistem mantendo a prática da agricultura e a criação de alguns animais. Essa questão revela o fato de que, a inserção desse grupo em específico, no ofício da costura, tem gerado conflitos de identidade entre o "ser agricultor" e o "ser costureiro", pois quando eu perguntava aos meus entrevistados qual era a profissão deles, por mais que quase todos costurassem por anos (alguns até mais de vinte anos), a maioria se auto classificava e se auto denominava como agricultor e não como costureiro.

O agricultor José, por exemplo, ao relatar sua experiência pessoal com a costura, diz ter aprendido a realizar essa atividade apenas observando o trabalho de seu irmão e sem hesitar, me falou que: "passei um bocado de tempo costurando, mas não quero nem ver uma máquina mais na minha frente. Eu não gosto não!". Ao justificar sua aversão pela profissão de costureiro, ele me conta sua trajetória: 
Eu fui embora para a rua (cidade), passei uma temporada por lá, trabalhando lá em fabrico, mas olhe o costurar é assim, é um compromisso muito grande porque os patrões vêm lá de fora, trazem as peças pra você fazer e dizem: - olha você vai ficar costurando só pra mim. Aí pronto, eu vou ter uma meta de fazer o tanto que ele pedir. Aí para você atingir aquela meta e não deixar o patrão na mão, porque você não vai farrapar com ele, né?! Aí você precisa ficar fazendo muito serão e eu não aguento não esse negócio de viver preso em casa. Só que o cabra tem que procurar a melhora dele né, e a melhora aqui é a sulanca!

Assim como seu irmão, José também foi para a cidade, mas não conseguiu ficar muito tempo por lá, o acesso à energia elétrica o possibilitou voltar para o sítio e ficar trabalhando em casa. Ele complementa sua fala justificando ainda que: "porque você tá tendo uma temporada que está sendo empregado em uma área que não é sua na que você gosta". E complementa sua fala afirmando que: "a gente aqui, mesmo com a dificuldade todinha, mas ser agricultor ainda é melhor do que trabalhar para os outros".

Os ideais de independência e liberdade estão sempre presentes nos depoimentos dos agricultores homens entrevistados e são fundamentais para refletir sobre a resistência ao ato de costurar. Para Shanin (2008), uma das peculiaridades do trabalho camponês é "o trabalho de um homem que é dono do seu próprio trabalho e pode decidir como utilizá-lo" (SHANIN, 2008, p. 38). Nesse sentido, o trecho acima é ilustrativo para demonstrar que na roça, o agricultor dispõe de seu tempo de maneira bem diferente do trabalho nas confecções, pois enquanto a demarcação do tempo e o ritmo de trabalho agrícola são estabelecidos por critérios da natureza, no trabalho com as confecções é o relógio físico e social que disciplinam o tempo, sempre controlado pelas demandas que devem ser cumpridas.

A diferença no ritmo de trabalho também é reclamada por eles, em função das longas cargas horárias, que em épocas de grandes demandas chegam a ser ilimitadas. Além disso, a posição dos mesmos enquanto agricultores permite que eles tenham um domínio maior sobre os processos de trabalho que realizam, já o papel de costureiros, aparece sob a forma de uma dominação, que passa a ser ditada por padrões e ordens externos.

Ao analisar as atividades de confecções em Santa Cruz do Capibaribe, Souza (2012) observou que para os trabalhadores, a relação ao tempo de trabalho se centra mais na possibilidade de "autonomia e controle sobre esse tempo do que propriamente das horas trabalhadas" (SOUZA, 2012, p.103). Sendo assim, segundo a autora, o que é considerado "ruim", não é apenas o fato de se trabalhar muito, mas sim o fato de ter um patrão.

Carneiro (2006) ao estudar as confecções familiares de Nova Friburgo no Rio de Janeiro, também observou algo semelhante ao que pode ser encontrado no Polo. Ela descreve que os pequenos agricultores de Nova Friburgo, também tinham o ideal de que as confecções de roupa representavam de alguma maneira um "aprisionamento", ou até mesmo uma "escravidão", enquanto o trabalho agrícola, mesmo não oferecendo grandes rendimentos, era sempre referenciado como um lugar de "liberdade".

Destarte, a pesquisa de campo revela que tanto a construção da identidade de agricultor, como a noção de uma masculinidade vinculada ao tipo de trabalho que está sendo realizado, faz com que eles acabem se diferenciando e até mesmo demarcando certa oposição ao ofício da costura. Além disso, a profissão de agricultor, referenciada por uma ideologia que expressa símbolos e práticas que valorizam o 
modo de vida camponês, denota características e representações que se aproximam da ideia da liberdade e independência no ato de não ter um patrão e tomar as próprias decisões, no afeto e amor pela terra, na vocação, no trabalho árduo, na valorização pelas tradições e na importância de produzir para alimentar. Já o trabalho com a costura elenca uma quebra dessa liberdade, pois exprime a dominação ou a sujeição a um patrão ou até mesmo aos meios de produção que acaba interiorizando a disponibilidade constante a alguém, como bem demonstrou José em sua fala, anteriormente.

A resistência à costura demonstrada pelos agricultores homens que entrevistei, me fez questioná-los se eles largariam a produção de roupas para trabalhar apenas com a agricultura e as respostas que obtive foram praticamente às mesmas. João, por exemplo, que costura desde a década de 90 me falou que "largava" com a seguinte condição:

Se o governo fizesse um esforço grande aí, colocasse aquelas máquinas que furam poço, nuns cantos desse eu não deixava a agricultura não. Se você tivesse aí uma irrigação pra manter uma agricultura, até em pouca terra dava pra produzir pra família, e se tivesse isso eu deixava a sulanca, porque a sulanca é um estresse da bexiga. Ela é boa e ao mesmo tempo é ruim, porque a vida do sítio é mais tranquila. Um irmão meu mesmo já disse, que prefere fazer cerca do que estar agarrado numa bexiga de uma máquina, mas eu como já estava mais ramificado na coisa, aí fiquei costurando. Agora já pensou se todo ano chovesse e tivesse lucro? Só costuro porque a precisão obriga, mas eu gosto mesmo é de trabalhar no campo, mas aqui não tem condição de viver só da roça.

João volta a tocar no ponto de que a sulanca é uma atividade estressante que "é boa e ao mesmo tempo é ruim", ou seja, o fato de que ela vem sendo a principal responsável pela renda das famílias rurais é visto como positivo, no entanto, o trabalho com a costura é visto como estressante e se opõe a tranquilidade da vida no campo.

Seguindo esse mesmo raciocínio, cabe ainda destacar o depoimento do agricultor Chico Carola, que também elenca elementos muito relevantes para essa discussão, pois ao ser indagado se os agricultores da região tivessem condições dignas de plantar e lucrar com essa atividade, eles voltariam exclusivamente para ela ou permaneceriam na costura, ele argumenta que:

Olha, eu acho que uma parte dos que estão na sulanca não voltavam não, porque eles não se habituam mais a trabalhar no pesado não, eles preferem ficar na sulanca. Os jovens de hoje em dia preferem trabalhar na sulanca ou em outro emprego do que na roça, porque a maioria deles não tem vocação para a agricultura não. Eu acho que já por conta do criar deles, que já foram criados nessa nova geração, incentivados pela costura e hoje eles não querem mais se voltar pra agricultura. E a agricultura é uma das fontes de renda que se o povo se dedicasse hoje era uma das coisas que daria mais dinheiro, porque se você fosse analisar a quantidade de pessoas que tem no Brasil e quantos trabalham na agricultura, e todos aqueles que vivem, todos eles precisam da agricultura. Quem é que vive sem comer? Sem uma camisa e sem uma calça boa a gente passa, mas duvido você viver sem se alimentar. 
É muito interessante o fato de Chico perceber a importância da agricultura, não só como uma fonte de renda, mas como uma atividade vital, porque nas suas palavras todas as pessoas que vivem necessitam dos alimentos produzidos pelos agricultores. Para ele a alimentação é muito mais importante do que o vestuário, pois sem roupas boas às pessoas conseguem sobreviver, mas sem comida não.

A fala de Chico se aproxima muito de algumas características encontradas por Seyferth (1984), que ao analisar o processo de industrialização do setor têxtil de Guabiruba, em Santa Catarina, observou como o significado da categoria "colono" tem mudado bastante nas últimas décadas, por conta da inserção de algumas pessoas em fábricas da região. No caso do Sul do país, ser colono é mais importante socialmente do que ser operário e semelhante ao que Chico narra em Pernambuco, existe uma valorização com relação aos dois tipos de trabalho (que no caso do Sul seria colonos-operários e do Nordeste agricultores-costureiros) que opõe produzir comidas e fabricar tecidos ou roupas. O primeiro, como aponta Seyferth (1984) sendo visto como mais importante e o segundo, sendo visto como supérfluo. A autora destaca ainda uma fala dos colonos que é praticamente igual ao que Chico relatou acima: "vai todo mundo para a fábrica e come o quê? Tecido não é comida. Um colono pode andar remendado, ter só uma roupa, mas sem comida não passa" (SEYFERTH, 1984, p. 91).

\section{CONSIDERAÇÕES FINAIS}

O crescimento das atividades não-agrícolas não só no Agreste pernambucano, mas também em outras regiões do Brasil e no mundo vem se constituindo como um elemento importante na atual fase de desenvolvimento da economia rural, pois tem criado novas oportunidades de trabalho para as famílias rurais, viabilizando práticas e estratégias dentro e fora dos estabelecimentos e também tem se apresentado como alternativa de renda complementar aos ganhos obtidos com as atividades agrícolas.

Diante das transformações econômicas, sociais e culturais em curso na contemporaneidade torna-se, cada vez mais necessário e importante uma visão sobre o mundo rural que esteja atenta para a complexidade, a vitalidade e a diversidade de seus processos. É importante, portanto, entender o rural como um espaço de múltiplas dimensões, e não apenas como um local onde se realizam atividades agrícolas ou pecuárias.

A preocupação com um rural que não é exclusivamente agrícola e com o conteúdo não restritamente produtivo da prática agrícola podem ser fatores decisivos para analisar os casos dos moradores desse meio que não tem condições de viver apenas da agricultura e suas diferentes formas de inserção na sociedade e na economia. Assim como observa Carneiro (2006), um olhar atento sobre essas questões pode tornar visível à contribuição não diretamente produtiva dos agricultores, independente do seu estatuto de produtor, pois permite também levar em conta outras formas de renda dos demais serviços oferecidos por esse grupo à sociedade.

Longe de considerar esse processo como linear, que afasta o camponês ou agricultor do meio rural, entende-se que a possível combinação de atividades, ou a recorrência a trabalhos não-agrícolas, ressalta cada vez mais a complexidade das formas e dos elementos utilizados por alguns atores para garantir sua manutenção e de sua família. Essa capacidade de adaptação frente aos novos contextos sociais e econômicos tem assumido práticas cada vez mais recorrentes no meio rural, e sob uma perspectiva sociológica podem até ser consideradas como mecanismos que asseguram a permanência das famílias agrícolas nas suas propriedades, conforme 
demonstrou Garcia Jr. (1989) para o caso de agricultores do brejo paraibano que se deslocaram para a região sul do país em busca de trabalho.

Buscou-se demonstrar através deste artigo que a fragilidade da atividade agrícola na região pesquisada é histórica, e por isso sempre encontrou dificuldades de se sustentar. A atividade com a costura por sua vez, tem desempenhado um papel importante no local e tem sido a garantia de renda para a reprodução de inúmeras famílias rurais. A pobreza, a escassez de terras e a falta de chuvas nunca permitiu que os pequenos agricultores pudessem se dedicar apenas à produção agrícola. Diante desse contexto, o recurso ao assalariamento temporário ou a venda de trabalho da mão de obra ociosa dos membros da família, para a complementação da renda doméstica, não é algo que aconteceu há pouco tempo, mas sempre foi uma estratégia utilizada historicamente na região, dentre as quais se destacam o trabalho alugado como uma das atividades mais recorrentes entre quase todas as famílias dos pequenos proprietários que por algum motivo, se viam impossibilitados de trabalharem nas suas próprias terras.

O que também se percebe através do caso trazido aqui é que mesmo diante da ausência de chuvas, alguns agricultores, sobretudo os homens mais velhos, tentam se manter resilientes e continuam plantando seus roçados e resistindo frente as crises climáticas e aos riscos do fracasso na colheita que podem correr. Conforme aponta Wanderley (2000), mesmo quando os agricultores são economicamente fragilizados e socialmente minoritários em alguns espaços locais, a atividade agrícola permanece "real e simbolicamente" como um dos eixos definidores das suas identidades. Sendo assim, a motivação destes agricultores e costureiros em manter a atividade agrícola é muito mais social e cultural, do que meramente econômica. Pois esta atividade está inserida em um modo de vida e que outros elementos devem ser levados em conta, tais como a manutenção da identidade social, de um patrimônio familiar, de redes de solidariedade e de sociabilidade (CARNEIRO, 2006). Além disso, o trabalho com a costura é visto como uma maneira de permanecer no campo, pois poder trabalhar em casa com as confecções de roupas evita que essas pessoas migrem para as cidades em busca de emprego.

No Agreste pernambucano a percepção do trabalho agrícola em oposição ao da costura para os trabalhadores homens envolvem vários elementos contrastantes, pois de um lado, encontramos os jovens e as mulheres que demonstram um maior interesse e preferência em costurar do que trabalhar na agricultura, e do outro, os homens agricultores e costureiros mais velhos, que mesmo não gostando do ofício da costura, reconhecem que de fato esta atividade vem possibilitando (com algumas ressalvas) uma melhora e mudança nas suas condições de vida, pois eles vêm conseguindo construir suas casas, comprar meios de transporte, aumentar seus patrimônios e até mesmo investir na agricultura ou na criação de animais com o dinheiro que ganham no trabalho com as confecções de roupas.

Por fim, convém destacar que com o desenvolvimento do Polo, os homens passam a exercer, profissionalmente, atividades que, na divisão tradicional do trabalho, quanto às relações de gênero, eram tipicamente atividades femininas (como costurar). Se, na origem dessa situação, certamente foram produzidos muitas aversões ou estigmas, atualmente já é possível notar que tal situação se encontra bastante naturalizada entre homens e mulheres. Entretanto, enquanto de um lado, a identidade feminina se constrói pautada tanto no trabalho como na família, do outro, permanecem inalteradas as responsabilidades das mesmas, diante da família e das atividades domésticas. Pois, o que se pode notar é que mesmo apesar dos homens realizarem atividades vistas como femininas, nas propriedades familiares rurais, em contramão a esse processo, não é nada simples separar o que é trabalho doméstico do que seria trabalho produtivo, como bem demonstra Paulilo (2004). Esse fator por 
sua vez, colabora para uma continuidade de modelos familiares patriarcais, que gera sobrecarga para as trabalhadoras mulheres, principalmente para aquelas que têm filhos pequenos, em virtude do tempo consumido em seus cuidados. Sendo assim, enquanto as mulheres atuam tanto na esfera produtiva, como na esfera reprodutiva, os homens se mantêm apenas na primeira destas.

\section{REFERÊNCIAS}

BEZERRA, E. M. O trabalho a domicílio das mulheres do Cariri Paraibano no Polo de Confecções do Agreste de Pernambuco. 2011. 132f. Dissertação (Mestrado em Ciências Sociais) - Programa de Pós-Graduação em Ciências Sociais, Universidade Federal de Campina Grande.

BURNETT, A. A "saga" dos retalheiros: um estudo sobre a instituição da Feira da Sulanca no Agreste pernambucano. Século XXI: Revista de Ciências Sociais, Santa Maria, v.3, n. 2, p.09-40, 2013.

BURNETT, A. "Era o tempo do pano na porta": Instituição e desenvolvimento da Feira da Sulanca dos anos 1950 aos anos 1980. 2014. 207f. Tese (Doutorado em Ciências Sociais) - Programa de Pós-Graduação em Ciências Sociais, Universidade Federal de Campina Grande.

CAMPELLO, G. M. C. A Atividade de confecções e a produção do espaço em Santa Cruz do Capibaribe. 1983. 157f. Dissertação (Mestrado em Geografia) Programa de Pós-Graduação em Geografia, Universidade Federal de Pernambuco.

CARDOSO DE OLIVEIRA, L. R. Pesquisa 'em' versus pesquisas 'com' seres humanos. In: CERES VICTORA et. al. (Orgs.). Antropologia e Ética: o debate atual no Brasil. Niterói: EdUFF, 2004.

CLIFFORD, J. A experiência etnográfica: antropologia e literatura no século XX. Rio de Janeiro: Editora da UFRJ, 1998.

CARNEIRO, M. J. T. Pluriatividade no campo: o caso francês. Revista Brasileira de Ciências Sociais, São Paulo, v.11, n.32, p.89-105, 1996.

CARNEIRO, M. J. T. Camponeses, agricultores e pluriatividade. Rio de Janeiro: Contra Capa Livraria, 1998.

CARNEIRO, M. J. T. Trabalho, "ajuda" e disputas: uma etnografia das confecções de lingerie em domicílios rurais. Estudos de Sociologia, Araraquara, v.11, n.20, p.99125, 2006.

ESPÍRITO SANTO, W. R. Sulanqueiras: o trabalho com vestuário e outros ofícios no agreste pernambucano. 2013. 490f. Tese (Doutorado em Antropologia) - Programa de Pós-Graduação em Antropologia Social, Universidade Federal do Rio de Janeiro.

GARCIA JR. A. R. Terra de Trabalho. Rio de Janeiro: Paz e Terra, 1983.

GARCIA JR., A. R. O Sul caminho do roçado: estratégias de reprodução camponesa e transformação social. São Paulo: Marco Zero, 1989. 
GRAZIANO DA SILVA, J.; DEL GROSSI, M. E. O Novo Rural Brasileiro. In: OFICINA DE ATUALIZAÇÃO TEMÁTICA, IAPAR. (Org.), v. I, 1992, Londrina, PR. Anais... ocupações rurais não-agrícolas. Londrina: Instituto Agronômico do Paraná, 2000.

LIRA, S. M. Os aglomerados de micro e pequenas indústrias de confecções do Agreste/PE: um espaço construído na luta pela sobrevivência. Revista de Geografia, Recife, v. 23, n. 1, p. 98-114, 2006.

LYRA, M. R. S. B. Sulanca x muamba: rede social que alimenta a migração de retorno. São Paulo Perspectiva, São Paulo, v.19, n.4, p.144-154, 2005.

MATTEI, L. A relevância da família rural como unidade de análise nos estudos sobre pluriatividade. Revista de Economia e Sociologia Rural, Brasília, v.45, n.4, p. 10551073, 2007.

PAULILO, M. I. S. O peso do trabalho leve. Ciência Hoje, Rio de Janeiro, v.5, n.28, p.64-70, 1987.

PAULILO, M. I. S. Trabalho familiar: uma categoria esquecida de análise. Revista Estudos Feministas, Florianópolis, v.12, n.1, p.229-252, 2004.

SALES, T. Agreste, Agrestes: Transformações recentes na agricultura nordestina. São Paulo: Editora Paz e Terra/CEBRAP, 1982.

SCHNEIDER, S. A pluriatividade na agricultura familiar brasileira. Porto Alegre: Editora da UFRGS, 2003.

SEYFERTH, G. Camponeses ou operários? O significado da categoria colono numa situação de mudança. Revista do Museu Paulista, São Paulo, v.29, (nova série), 1984.

SHANIN, T. Lições Camponesas. In: PAULINO, E. T.; FABRINI, J. E. (Orgs.). Campesinato e Territórios em Disputa. São Paulo: Expressão Popular, 2008.

SILVA, S. R. A. A juventude na "Sulanca": Os desafios da inserção no mundo do trabalho em Taquaritinga do Norte - PE. 2009. 176f. Dissertação (Mestrado em Ciências Sociais) - Programa de Pós-Graduação em Ciências Sociais, Universidade Federal de Campina Grande.

SOUZA, A. M. "A gente trabalha onde a gente vive": A vida social das relações econômicas: parentesco, "conhecimento" e as estratégias econômicas no Agreste das confecções. 2012. 228f. Dissertação (Mestrado em Antropologia) - Programa de Pósgraduação em Sociologia e Antropologia, Universidade Federal do Rio de Janeiro.

TEPICHT, J. Marxisme et Agriculture: le paysan polonais. Paris: Armand Colin, 1973.

VÉRAS DE OLIVEIRA, R. O Polo de Confecções do Agreste de Pernambuco: ensaiando uma perspectiva de abordagem. In: ARAÚJO, A. M. C.; VÉRAS DE OLIVEIRA, R. (Orgs.). Formas de trabalho no capitalismo atual: condição precária e possibilidades de reinvenção. São Paulo: Annablume, 2011. 
VIRGOLIN, I. W. C.; HILLIG, C.; FROEHLICH, J. M. Um estudo sobre os sentidos do trabalho para os agricultores familiares a partir da pluriatividade. Extensão Rural, Santa Maria, v. 22, n.4, p.116-135, out./dez. 2015. Disponível em: https://periodicos.ufsm.br/extensaorural/article/view/10499. Acesso em: 02 dez. 2018.

WANDERLEY, M. N.B. Raízes históricas do campesinato brasileiro. In: TEDESCO, J. C. (Org). Agricultura familiar: realidade e perspectivas. Passo Fundo: UPF, 1998.

WANDERLEY, M. N. A emergência de uma nova ruralidade nas sociedades modernas avançadas - o rural como espaço singular e ator coletivo. Estudos sociedade e Agricultura, v.8. n.2, 2000. 